\title{
Why can arrowhead scales, Unaspis yanonensis Kuwana (Homoptera: Diaspididae), which burrow and settle below conspecifics, successfully avoid attack by its parasitoid, Coccobius fulvus Compere et Annecke (Hymenoptera: Aphelinidae)?
}

\author{
Takashi Matsumoto, ${ }^{1, *, \dagger}$ Takao ITIOKA ${ }^{2}$ and Takayoshi NiSHIDA ${ }^{1}$ \\ ${ }^{1}$ Laboratory of Insect Ecology, Graduate School of Agriculture, Kyoto University; Kyoto 606-8502, Japan \\ ${ }^{2}$ Laboratory of Applied Entomology, Graduate School of Bioagricultural Sciences, Nagoya University; Nagoya 464-8601, Japan
}

(Received 8 July 2003; Accepted 20 October 2003)

\begin{abstract}
When arrowhead scales, Unaspis yanonensis Kuwana (Homoptera: Diaspididae), burrow and settle underneath conspecifics (i.e., burrowers), the burrowers are less vulnerable to attack by the parasitoid wasp Coccobius fulvus Compere et Annecke (Hymenoptera: Aphelinidae) than scales that settle singly (i.e., singletons). To examine how this differential susceptibility between settling modes occurs during the host-finding and oviposition processes of the parasitoid, we observed the foraging behavior of the parasitoids in the laboratory. Encounter rates between parasitoids and hosts were similar between settling modes. When scales that had been burrowed under (burrowees) were alive, the parasitoids oviposited in them as frequently as in singletons, however, the wasps did not lay eggs in burrowers. When burrowees were dead or parasitized, the parasitoids did not exhibit oviposition behavior and left soon after they had drummed these individuals several times with their antennae. Our results strongly suggest that the parasitoids were unable to identify the burrowers. Based on this study, we discuss which stimuli may be used by the parasitoids as cues to locate hosts.
\end{abstract}

Key words: Foraging behavior; parasitoid avoidance; susceptibility to parasitism; Unaspis yanonensis; Coccobius fulvus

\section{INTRODUCTION}

A central theme in the theory of host-parasitoid systems is the link between parasitoid foraging behavior and the stability of the host-parasitoid system (Godfray, 1994; Reeve et al., 1994a, b). One of the most probable mechanisms contributing to the stability of such systems is the existence of a spatial refuge (Kuno, 1987). Theory suggests that a relatively constant refuge that leaks recruits to the rest of the population can be stabilizing (Bailey et al., 1962; Hassell and May, 1974; Maynard Smith, 1974; Beddington et al., 1978; May, 1978; Kuno, 1987; Holt and Hassell, 1993; Reeve et al., 1994a, b; Lynch et al., 1998). Only a few studies, however, have shown why individuals within a refuge are less susceptible to parasitism in terms of the foraging behavior of a parasitoid (but see Murdoch et al., 1989, 1996; Walde et al., 1989; Itioka and Inoue, 1996a, b).

The arrowhead scale, Unaspis yanonensis Kuwana, is one of the most serious insect pests of citrus trees in Japan (Ohgushi, 1969; Inoue and Ohgushi, 1976, 1977). In 1980, two species of parasitoids, Aphytis yanonensis DeBach et Rosen and Coccobius fulvus Compere et Annecke were introduced from the People's Republic of China as biological control agents (Nishino and Takagi, 1981; Takagi, 1983; Furuhashi and Nishino, 1984, 1994). Since their introduction, these parasitoids have not only suppressed the scale density at well below the economic threshold (Furuhashi and Nishino, 1983, 1994; Hashimoto et al., 1985; Takagi and Ujiye, 1986; Itioka et al., 1997), but they have also maintained the scale populations at extremely low densities for over 14 years (Matsumoto et al., 2003b).

Matsumoto et al. (2003a) demonstrated that a spatial refuge exists in scale populations. Some

\footnotetext{
* To whom correspondence should be addressed at: E-mail: r47462a@nucc.cc.nagoya-u.ac.jp

$\dagger$ Present address: Laboratory of Applied Entomology, Graduate School of Bioagricultural Sciences, Nagoya University, Nagoya 464-8601, Japan
} 
scales (hereafter referred to as burrowers) burrow and settle underneath conspecifics, thereby more successfully avoiding parasitoid attacks than other scales (singletons), which suggests that burrowers contribute to the stability of the systems observed in the field. The aim of our study was to elucidate why burrowers are less susceptible to parasitism by observing the searching and oviposition behaviors of the parasitoids, and to explain the stability of the host-parasitoid system with the foraging behavior of the parasitoid.

\section{MATERIALS AND METHODS}

We examined only one parasitoid species, C. ful$v u s$. This species alone played an important role in suppressing and maintaining scale populations at extremely low levels at our study site (Itioka et al., 1997; Matsumoto et al., 2003b), which is a ca. 1-ha Satsuma mandarin orange (Citrus unshiu Marc.) grove in Wakayama Prefecture, central Japan, containing 500 trees [see Itioka et al. (1992) for a detailed description of the study site]. Although two species of parasitoids were originally released at this site, it is difficult to sample an adequate number of the second species, A. yanonensis, due to its small population size.

Life history of the host: $\boldsymbol{U}$. Yanonensis. Details of the life history of the arrowhead scale were provided by Ohgushi (1969). The arrowhead scale has two generations in Japan; the first occurs in early summer and the second in late summer (Furuhashi and Nishino, 1983, 1994; Itioka et al., 1992). A female scale can produce up to 170 crawlers in her lifetime (Okudai et al., 1966). Females pass through two larval instars and one immature adult stage before maturing. Females remain sessile after locating a settling site within a few hours after hatching (Ohgushi, 1969). This scale is sexually dimorphic. Males pupate at the end of the second instar, emerge, and fly away to mate.

Life history of the parasitoid: $\boldsymbol{C}$. fulvus. The basic biology of the parasitoid is described in Takagi and Hirose (1994). C. fulvus reproduces sexually, with a 1:1 sex ratio and has approximately five generations a year (Furuhashi and Nishino, 1983, 1994). The total numbers of eggs laid per female is $60.6 \pm 3.87$ (Mean \pm S.E.; Takagi and Ogata, 1990). This species is endoparasitic: eggs are laid within the hosts (immature and ma- ture adult female scales).

Definition of the settling mode. If two individuals settle so that they overlap vertically, with the lower individual covered completely by the shell of the upper individual, we define the settling mode as "double settling", and refer to the lower individual as the burrower and the upper one as the burrowee (Matsumoto et al., 2003a). Observation of the settling behavior of crawlers confirmed that double settling resulted from the settling behavior of the burrower, which burrowed and settled under a conspecific that had already settled (Matsumoto et al., 2003a). We defined all other settling modes as single settling, because partially overlapping scales were rare and could be ignored.

Rearing of hosts and parasitoids. Parasitoids were reared according to the methods described by Sugiura (1997). We sampled approximately 200400 leaves from 12 trees that had a relatively high scale density in mid-February 2000 at a citrus grove in Wakayama. Leaves were brought to the laboratory, and scales infesting these leaves were dissected under a binocular microscope $(\times 10$ magnification) to sample late-instar larvae and pupae of C. fulvus. Late-instar larvae and pupae were kept in plastic cups ( $85 \mathrm{~mm}$ diameter, $40 \mathrm{~mm}$ depth) that were placed in a growth chamber (temperature: $25^{\circ} \mathrm{C}$; photoperiod: $\left.16 \mathrm{~L}-8 \mathrm{D}\right)$. Eclosion of the parasitoids was checked every day. After observing mating, eclosed females were transferred to plastic cases $(350 \times 255 \times 62 \mathrm{~mm})$ containing Satsuma mandarin orange leaves infested with arrowhead scales. Leaf petioles were covered with absorbant cotton to prevent leaf quality from deteriorating. All scales in each plastic case were dissected to collect the pupae of the wasps 25 days after their introduction, when most of the parasitoids within the hosts were in the pupal stage. Again, pupae were stored in plastic cups in the growth chamber. This procedure was repeated. Before the observations of parasitoid behavior, pupae were separated individually into plastic cups $(85 \mathrm{~mm}$ diameter; $40 \mathrm{~mm}$ depth), to ensure that mating occurred only once; the bottoms of the cups were coated with honey.

Scales used as hosts both in the laboratory experiments and in wasp husbandry were reared on a Satsuma mandarin orange tree at an experimental farm of Kyoto University; these scales were reared within a Tetron gauze bag to protect them from 
parasitoid attacks. To allow for parasitization, some scales were reared on the same tree without Tetron gauze bags.

Observation of parasitoid foraging behavior in the laboratory. Observations of the parasitoid host-searching and oviposition behaviors were conducted according to Sugiura (1997). Undamaged current-year leaves were sampled from a citrus tree at an experimental farm of Kyoto University. Leaves were cut into pieces $(30 \times 30 \mathrm{~mm})$, rinsed with distilled water, and air-dried. We used water to attach an immature adult female scale to the center of each piece of leaf. We experimentally generated double settling by attaching a parasitized, live or dead, immature adult female above the scale that had previously been attached to the leaf piece. We did this for several reasons. First, because it was necessary to remove the burrowee to identify the burrower, it was impossible for us to use natural double-settled scales in our observations. Furthermore, we tried to exclude any unknown factors that could possibly affect the susceptibility of the scales to parasitism.

A piece of leaf with a scale on it was placed in the center of a petri dish $(150 \mathrm{~mm}$ diameter; $15 \mathrm{~mm}$ depth). A two-day-old female parasitoid that had been mated one day before the experiment was transferred onto the piece of leaf with as little disturbance as possible. We then observed its foraging behavior under a binocular microscope $(\times 10$ magnification). Parasitoids used in the experiment were allowed to oviposit in an immature adult female scale 30-60 min before the beginning of the experiments.

The sequence of foraging behavior by the parasitoid, from host-finding to ovipositing on a leaf, is as follows (Sugiura, 1997). When the parasitoid encounters a scale while searching on a leaf, it first drums on the scale with its antennae. It then drills through the shell of the scale with its ovipositor and begins to lay an egg. This sequence of parasitoid foraging behavior can be divided into the following three processes: host finding, host acceptance, and oviposition. For each of these processes, we adopted the following indices: the frequency with which the scales were drummed (i.e., drumming rate $=$ number of scales drummed/number of scales provided) as an index of host-finding efficiency; the duration of continuous drumming as an index of host quality; and oviposition rate after finding (i.e., number of scales in which eggs were laid/number of scales that were drummed) as an index of ovipositing efficiency. Sugiura (1997) demonstrated in the same host-parasitoid system that the duration of drumming behavior was a good index of host quality: When the parasitoid encountered living, unparasitized scales, it drummed the scales significantly longer than dead, or parasitized ones. These indices were compared among settling modes (double settling in which the burrowee was alive, dead, or parasitized, and single settling. In all cases of double settling, burrowers were alive). The drumming rate was adopted to ascertain that the encounter rates between the parasitoids and hosts were similar among the settling modes. If the parasitoid can not recognize burrowers in the double settling, the duration of continuous drumming for double settled pairs whose burrowees were dead, or parasitized was significantly shorter than those for singletons and double settling whose burrowees were alive. In cases where the ovipositing efficiency was different among settling modes though the parasitoid was able to find burrowers as efficiently as singletons, only the oviposition rate after finding differed.

Finally, the success rate of oviposition (i.e., number of scales in which eggs were laid/number of scales provided) was compared among burrowers, burrowees, and singletons. Whether the parasitoid successfully oviposited, or in which scale (burrowee or burrower) eggs were laid when a parasitoid oviposited in double-settled individuals, was determined by dissection of the scales after the parasitoid had left. Parasitoids are able to distinguish live scales from dead and parasitized ones (Sugiura, 1997), and do not oviposit within dead or parasitized scales. Therefore, dead and parasitized scales were excluded from the calculation of the success rate of oviposition. In cases when a wasp did not encounter a scale within five minutes from the transfer of the parasitoid, observations were stopped. Observations were repeated 25 times for each settling mode.

\section{RESULTS}

Drumming rates as an index of frequency of host finding did not differ among settling modes (Fig. 1, adjusted $G=1.91, p=0.59, G$-test). For every settling mode, more than half of the scales provided 


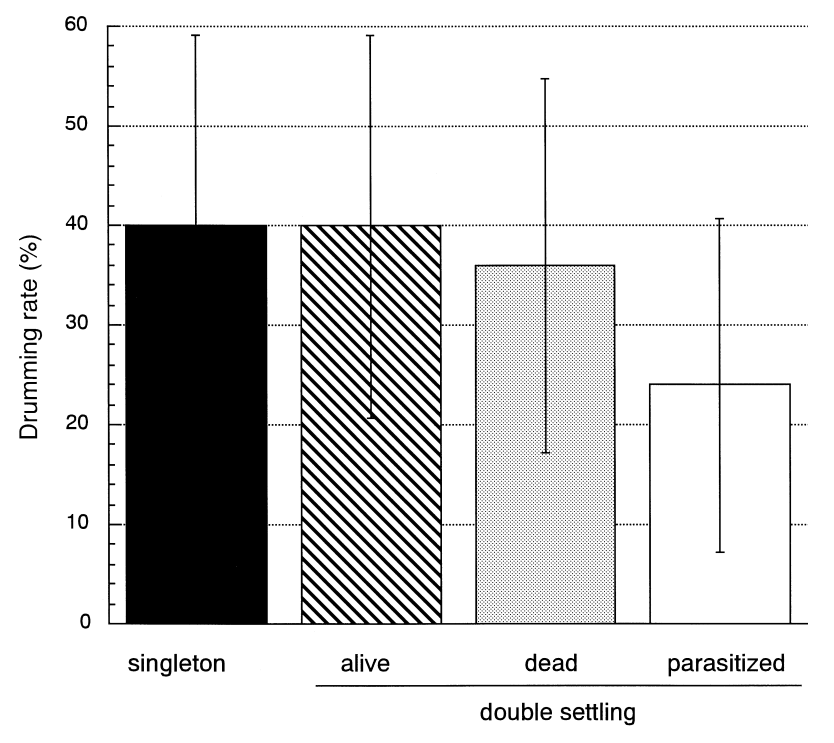

Settling mode

Fig. 1. Comparison of drumming rates ( $\pm 95 \%$ C.I.) among settling modes as an index of host-finding efficiency. In all double settlings, burrowers were alive. Closed, striped, dotted, and open bars represented the drumming rates for single and double-settled scales whose burrowees were alive, dead, or parasitized, respectively. There were no significant differences among settling modes $(n=100$, adjusted $G=1.91 p=0.59, G$ test).

were not drummed.

Duration of continuous drumming as an index of host quality was significantly different among settling modes (Fig. $2, \chi^{2}=18.21, p<0.001$, Log-rank test). The duration of drumming behavior for singletons was not significantly different from that for double-settled pairs whose burrowee was alive (Fig. 2, $\chi^{2}=0.0001, p=0.99$, Log-rank test). However, the drumming times of the above two settling modes were significantly longer than those of double-settled individuals whose burrowees were dead or parasitized (Fig. 2, $p<0.05$, Log-rank test after Bonferroni's correction).

A significant difference in oviposition rates after host-finding as an index of oviposition efficiency was found among settling modes (Fig. 3, adjusted $G=14.68, p<0.01, G$-test). Oviposition rates after host-finding in the former two cases were significantly higher than those of the latter two (Fig. 3, $p<0.05, G$-test). Continuous drumming times were significantly related to oviposition success $(n=35$, $G=27.69, p<0.0001$, logistic regression analysis).

When parasitoids oviposited in double-settled individuals, all of the eggs were laid within the

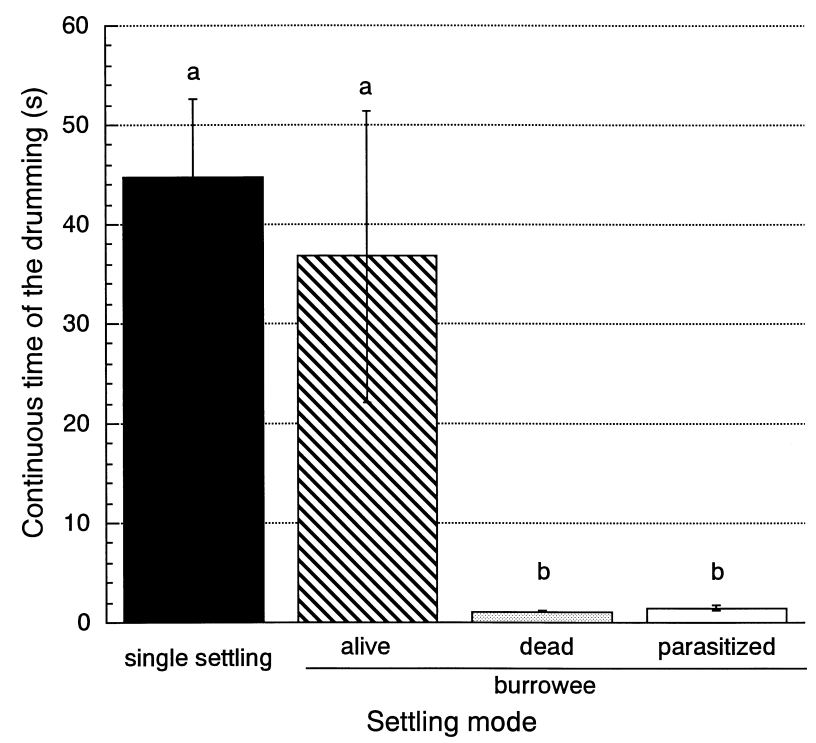

Fig. 2. Comparison of the duration of continuous drumming ( \pm S.E.) among settling modes as an index of host quality. In any double settlings, burrowers were alive. Closed, striped, dotted, and open bars represented the drumming duration for single and double-settled scales whose burrowees were alive, dead, or parasitized, respectively. Different letters above the bars represent significant differences among settling modes ( $n=100, p<0.05$, Log-rank test after Bonferroni's correction).

burrowees. Success rates of oviposition were significantly different among settling modes (Fig. 4, $G=20.14, p<0.0001, G$-test $)$. Success rates of oviposition in the burrower were significantly lower than in the burrowee or in singletons (Fig. 4, $p<$ $0.0001, G$-test).

\section{DISCUSSION}

There are two possible hypotheses to explain the lower susceptibility of the burrowers to parasitism: 1) The probability of finding a burrower is lower than the probability of finding a singleton. 2) A parasitoid can find burrowers as frequently as single scales, but oviposition preference for the burrower is lower than for the singleton because the parasitoid must drill through two shells to oviposit; alternatively, it may not be able to lay eggs inside the burrower because its ovipositor is too short. To examine which hypothesis is appropriate, we observed the foraging behaviors of the parasitoids in the laboratory. Our study supports the former hypothesis, i.e., parasitoids are unable to find burrowers even when they find burrowees, although the parasitoids successfully found and laid eggs in bur- 


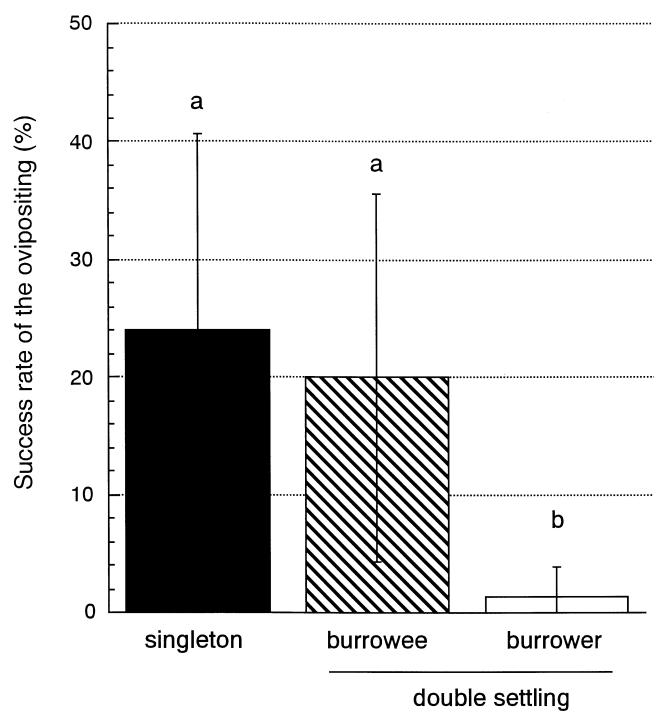

Settling mode

Fig. 3. Comparison of the oviposition rates after host finding ( $\pm 95 \%$ C.I.) as an index of oviposition efficiency. In all double settlings, burrowers were alive. Closed, striped, dotted, and open bars represented the oviposition rates for single and double-settled scales whose burrowees were alive. None of the wasps oviposited in double-settled scales whose burrowees were dead or parasitized. Different letters above the bars represented significant differences among settling modes $(n=100$, $p<0.05, G$-test).

rowees as frequently as in singletons. Therefore, when a parasitoid, being able to distinguish live from dead or parasitized scales (Sugiura, 1997), finds dead or parasitized burrowees below dead or parasitized burrowees, it ceases to drum and does not attempt to drill through the shell of the scale, which is typically the last step after drumming in the series of oviposition behaviors (Sugiura, 1997). If the wasps had been able to find burrowers, then they should have drummed longer than observed and should have attempted to oviposit in the burrowers. In this study, all successful oviposition events were preceded by the drumming of the scales in which the wasps laid their eggs and duration time had a significant positive relationship with the success of oviposition. Drumming the host may be essential to initiate oviposition. It is possible that the parasitoids could not identify burrowers because they were unable to drum the burrowers directly. The burrowers can avoid parasitoid attack more successfully by escaping from being found, which is the best defense tactic against natural enemies (Evans and Schmidt, 1990).

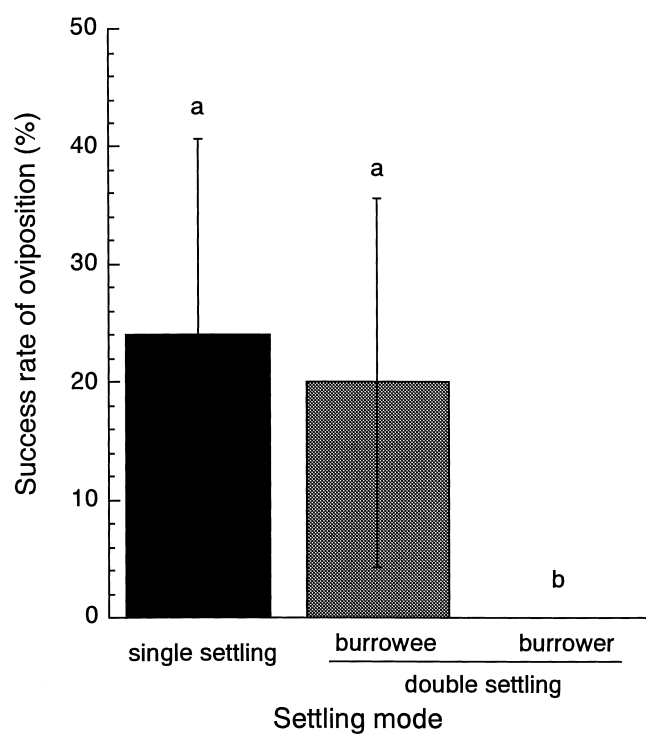

Fig. 4. Comparison of the success rate of oviposition ( $\pm 95 \%$ C.I.) among settling modes. Closed and shaded bars represent the success rate for singletons and burrowees. No burrower was successfully parasitized. Dead and parasitized burrowees were excluded from the calculations. Different letters above the bars represented significant differences among settling modes $(n=125, p<0.001, G$-test $)$.

It is impossible to elucidate whether parasitoids use olfactory cues from the hosts, or whether they randomly search leaves for potential hosts. Parasitoids introduced to petri dishes, however, seemed to wander on leaves and occasionally drummed the surface of the leaves though several parasitoids approached the scales directly. Thus, these laboratory observations suggest that the parasitoids search for hosts randomly, at least on a leaf, without using olfactory cues derived directly from the host. This speculation is supported by the wasps' inability to find the burrowers. If the wasps used olfactory cues, then they should have drummed double-settled individuals whose burrowees were dead or parasitized for a longer time than we observed, because they would have detected the odor from the live burrower.

The success of parasitization can be divided into four processes: habitat finding, host finding, host acceptance, and survival within the host (Doutt, 1959, 1964; Flanders, 1959; Vinson, 1976, 1984, 1985; Vinson and Iwantsch, 1980; Nordlund et al., 1981; van Alphen and Vet, 1986; Wellings, 1991). We assumed that the process of habitat finding was identical between singletons and burrowers, because they settled on the same leaves. Therefore, 
only the host-finding and host-acceptance processes, not survival within the host, were examined.

In the field, burrowers are smaller than singletons (Matsumoto et al., 2002). If the parasitoids prefer larger scales as hosts as a result of better performance within larger hosts, then we would underestimate the lower susceptibility of burrowers to parasitism. In contrast, if the parasitoids prefer smaller scales because it takes less time to drill through their thinner shells, we would overestimate the lower susceptibility of the burrowers. In our study, no burrowers were parasitized, while burrowers in the field suffered from approximately $10 \%$ parasitism, which was lower than the parasitism of singletons (approximately 40\%; Matsumoto et al., 2003a). The parasitoids may prefer burrowers to single scales for ovipositing due to their smaller body size, or other unknown factors might allow the parasitoids to find burrowers more easily than observed in the laboratory. Thus, future research on the relationship between body size of the host and oviposition preference would be valuable to explain the difference in rates of parasitism between that observed in the field and in the laboratory.

Sugiura (1997) demonstrated that parasitoids drummed almost all of the scales provided in the same arena experiment, while they drummed only $40 \%$ of the scales used in our study. Sugiura (1997) used leaves infested by scales, whereas we attached hosts to uninfested leaves. It has been reported that some parasitoids use herbivore-induced plant volatiles (HIPV) as cues in host searching (Vet et al., 1991; Vet and Dicke, 1992; Takabayashi and Dicke, 1996). The efficiency of host finding described by Sugiura (1997) might have been higher than that in our study because the parasitoids also made use of HIPV in their host search. In addition, scales form a glaucous-colored circle around the settling point on a leaf (Itioka pers. comm.); the parasitoids might use the physical and/or physiological changes in the leaf caused by scales infesting in their search. To explain the stability of the systems in terms of the foraging tactic of the parasitoid more completely, further research is required.

\section{ACKNOWLEDGEMENTS}

We thank Messrs. T. Matsumoto and Y. Nakata for permis- sion to use their citrus orchards. We also thank Dr. N. Sugiura (Kumamoto Prefectural Pest and Disease Management Center) for valuable advice about the parasitoid, and Dr. K. Furuhashi for his imformative suggestion about the scale. We are thankful to Dr. N. Ishida (Kyoto University) and the members of the Kyoto Group for the Reduction of Agrochemical Pesticides (KGRAP) for providing help with the field experiment. This study was partly supported by a Grant-in-Aid (\#13440230) from the Ministry of Education, Culture, Sports, Science and Technology, Japan.

\section{REFERENCES}

Bailey, V. A., A. J. Nicholson and E. J. Williams (1962) Interactions between hosts and parasites when some host individuals are more difficult to find than others. $J$. Theor. Biol. 3: 1-18.

Beddington, J. R., C. A. Free and J. H. Lawton (1978) Characteristics of successful natural enemies in models of biological control of insect pests. Nature 273: 513-519.

Doutt, R. L. (1959) The biology of parasitic Hymenoptera. Annu. Rev. Entomol. 4: 161-182.

Doutt, R. L. (1964) Biological characteristics of entomophagous adults. In Biological Control of Insect Pests and Weeds (P. DeBach ed.). Reinhold, New York, pp 145-167.

Evans, D. L. and J. O. Schmidt (eds.) (1990) Insect Defenses. State University of New York Press, Albany. 482 pp.

Flanders, S. E. (1959) Differential host relations of the sexes in parasitic Hymenoptera. Entomol. Exp. Appl. 2: $125-142$.

Furuhashi, K. and M. Nishino (1983) Biological control of arrowhead scale, Unaspis yanonensis, by parasitic wasps introduced from the People's Republic of China. Entomophaga 28: 277-286.

Furuhashi, K. and M. Nishino (1984) Introduced natural enemies of the arrowhead scale, Unaspis yanonensis Kuwana, and its control effects. Plant Protect. 38: 258-262 (in Japanese).

Furuhashi, K. and M. Nishino (1994) Biological control of arrowhead scale Unaspis yanonensis Kuwana by natural enemies introduced from the People's Republic of China. Special Bull. No.6 Shizuoka Pref. Citrus Exp. Stn. 65 pp. (in Japanese with English summary).

Godfray, H. C. J. (1994) Parasitoids. Princeton University Press, Princeton, New Jersey. 473 pp.

Hashimoto, S., S. Mizushima and M. Kohno (1985) Biological control of the arrowhead scale, Unaspis yanonensis, by aphelinid parasites introduced from the People's Republic of China. 1. Effect of release of the natural enemies in Amami-oshima, Kagoshima Prefecture. Proc. Assoc. Pl. Prot. Kyushu 31: 204-205 (in Japanese).

Hassell, M. P. and R. M. May (1974) Aggregation in predators and insect parasites and its effect on stability. $J$. Anim. Ecol. 43: 567-594.

Holt, R. D. and M. P. Hassell (1993) Environmental heterogeneity and the stability of host-parasitoid interactions. J. Anim. Ecol. 62: 89-100.

Inoue, T. and R. Ohgushi (1976) A simulation model of the arrowhead scale population on a citrus tree in relation to 
control programmes (1). Res. Popul. Ecol. 18: 89-104.

Inoue, T. and R. Ohgushi (1977) A simulation model of the arrowhead scale population on a citrus tree in relation to control programmes (2): dispersal of the scale and the amount of petroleum oil. Res. Popul. Ecol. 18: 302318.

Itioka, T. and T. Inoue (1996a) Density-dependent ant attendance and its effect on the parasitism of a honeydew-producing scale insects, Ceroplastes rubens. Oecologia 106: 448-454.

Itioka, T. and T. Inoue (1996b) The role of predators and attendant ants in the regulation and persistence of a population of the citrus mealbug Pseudococcus citriculus in a satsuma orange orchard. Appl. Entomol. Zool. 31: 195-202.

Itioka, T., T. Inoue and N. Ishida (1992) A ten-year study of population dynamics of citrus pests in the pesticide-reduced orchard. Res. Popul. Ecol. 34: 227-247.

Itioka, T., T. Inoue, T. Matsumoto and N. Ishida (1997) Biological control by two exotic parasitoids: eight-year population dynamics and life tables of the arrowhead scale. Entomol. Exp. Appl. 85: 65-74.

Kuno, E. (1987) Principles of predator-prey interaction in theoretical, experimental, and natural population systems. Adv. Ecol. Res. 16: 249-337.

Lynch, L. D., R. G. Bowers, M. Begon and D. J. Thompson (1998) A dynamic refuge model and population regulation by insect parasitoids. J. Anim. Ecol. 67: 270-279.

Matsumoto, T., T. Itioka and T. Nishida (2002) Fitness cost of parasitoid avoidance behaviour in the arrowhead scale, Unaspis yanonensis. Entomol. Exp. Appl. 105: 83-88.

Matsumoto, T., T. Itioka and T. Nishida (2003a) Rapid change in the settling behaviour of the arrowhead scale Unaspis yanonensis as an avoidance mechanism against introduced parasitoids, Aphytis yanonensis and Coccobius fulvus. Entomol. Exp. Appl. 107: 105-113.

Matsumoto, T., T. Itioka, T. Nishida and T. Inoue (2003b) Introduction of parasitoids has maintained a stable population of arrowhead scales at extremely low levels. Entomol. Exp. Appl. 106: 115-125.

May, R. M. (1978) Host-parasitoid systems in patchy environments: a phenomenological model. J. Anim. Ecol. 47: 833-844.

Maynard Smith, J. (1974) Models in Ecology. Cambridge University Press, Cambridge. 145 pp.

Murdoch, W. W., R. F. Luck, S. J. Walde, J. D. Reeve and D. S. Yu (1989) A refuge for red scale under control by Aphytis: structual aspects. Ecology 70: 1707-1714.

Murdoch, W. W., S. L. Swarbrick, R. F. Luck, S. Walde and D. S. Yu (1996) Refuge dynamics and metapopulation dynamics: an experimental test. Am. Nat. 147: 424-444.

Nishino, M. and K. Takagi (1981) Parasitoid wasps of Unaspis yanonensis introduced from China. Plant Protect. 35: 253-256 (in Japanese).

Nordlund, D. A., R. L. Jones and W. J. Lewis (eds.) (1981) Semiochemicals, Their Role in Pest Control. John Wiley, New York. 306 pp.

Ohgushi, R. (1969) Ecology of Insects and Pests on Citrus. Noson-gyoson Bunka Kyokai, Tokyo. 244 pp. (in Japa- nese).

Okudai, S., R. Korenaga and Y. Ando (1966) On the seasonal appearance of larva of the arrowhead scale, Unaspis yanonensis. Bull. Fruit Tree Res. Stn. B5: 149-163 (in Japanese with English summary).

Reeve, J. D., J. T. Cronin and D. R. Strong (1994a) Parasitism and generation cycles in a salt-marsh planthopper. J. Anim. Ecol. 63: 912-920.

Reeve, J. D., J. T. Cronin and D. R. Strong (1994b) Parasitoid aggregation and the stabilization of a salt marsh host-parasitoid system. Ecology 75: 288-295.

Sugiura, N. (1997) Interspecific competition between Aphytis yanonensis DeBach et Rosen and Coccobius fulvus Compere et Annecke (Hymenoptera: Aphelinidae), introduced parasitoids of Unaspis yanonensis Kuwana (Homoptera: Diaspididae), and their coexistence in the field. Docter thesis, Kyushu University, Fukuoka. 121 pp. (in Japanese with English summary).

Takabayashi, J. and M. Dicke (1996) Plant-carnivore mutualism through herbivore-induced carnivore attractants. Trends Plant Sci. 1: 109-113.

Takagi, K. (1983) Establishment Aphytis sp. and Physcus fulvus (Hymenoptera: Aphelinidae), the imported parasitoids of arrowhead scale, Unaspis yanonensis (Homoptera: Diaspididae), on citrus orchard in Japan. Bull. Fruit Tree Res. Stn. D5: 93-110 (in Japanese with English summary).

Takagi, K. and T. Ujiye (1986) Suppressive effects on the arrowhead scale, Unaspis yanonensis (Hemiptera: Diaspididae) of the introduced parasitoids, Aphytis yanonensis and Coccobius fulvus (Hymenoptera: Aphelinidae). Bull. Fruit Tree Res. Stn. D8: 53-64 (in Japanese with English summary).

Takagi, M. and Y. Hirose (1994) Building parasitoid communities: the complementary role of two introduced parasitoid species in a case of successful biological control. In Parasitoid Community Ecology (B. A. Hawkins and W. Sheehan eds.). Oxford University Press, Oxford, pp. 437-447.

Takagi, M. and T. Ogata (1990) Reproductive potential of Aphytis yanonensis (DeBach et Rosen) and Coccobius fulvus (Compere et Annecke) (Hymenoptera: Aphelinidae), parasitoids of Unaspis yanonensis (Kuwana) (Homoptera: Diaspididae). Appl. Entomol. Zool. 25: 407-408

van Alphen, J. J. M. and L. E. M. Vet (1986) An evolutionary approach to host finding and selection. In Insect Parasitoids (J. K. Waage and D. Greathead eds.). Academic Press, London, pp. 23-61.

Vet, L. E. M. and M. Dicke (1992) Ecology of infochemical use by natural enemies in a tritrophic context. Annu. Rev. Entomol. 37: 141-172.

Vet, L. E. M., F. L. Wåker and M. Dicke (1991) How to hunt for hinding host: the reliability-detectability problem in foraging parasitoids. Neth. J. Zool. 41: 202-213.

Vinson, S. B. (1976) Host selection by insect parasitoids. Annu. Rev. Entomol. 21: 109-133.

Vinson, S. B. (1984) How parasitoids locate their hosts: a case of insect espionage. In Insect Communication ( $\mathrm{T}$. 
Lewis ed.). Academic Press, London, pp. 325-348.

Vinson, S. B. (1985) The behavior of parasitoids. In Comprehensive Insect Physiology, Biochemistry and Pharma$\operatorname{cology}$ (G. A. Kerkut and L. I. Gilbert eds.). Pergamon Press, New York, pp. 417-469.

Vinson, S. B. and G. F. Iwantsch (1980) Host suitability for insect parasitoids. Annu. Rev. Entomol. 25: 397-419.
Walde, S. J., R. F. Luck, D. S. Yu and W. W. Murdoch (1989) A refuge for red scale: the role of size-selectivity by a parasitoid wasp. Ecology 70: 1700-1706.

Wellings, P. W. (1991) Host location and oviposition on animals. In Reproductive Behavior of Insects (W. J. Bailey and J. Ridsdill-Smith eds.). Chapman and Hall, Melbourne, pp. 75-107. 